\title{
Rapid detection of the factor XIII Val34Leu (163 G $\rightarrow$ T) polymorphism by real-time PCR using fluorescence resonance energy transfer detection and melting curve analysis
}

\author{
Amir H. Shemirani ${ }^{1}$ and László Muszbek ${ }^{2,3, *}$ \\ ${ }^{1}$ Department of Clinical Biochemistry and Molecular \\ Pathology, \\ ${ }^{2}$ Clinical Research Center, \\ Medical and Health Science Center, University of \\ Debrecen, Debrecen, Hungary \\ 3 Thrombosis Research Group of the Hungarian \\ Academy of Sciences, Debrecen, Hungary
}

\begin{abstract}
The Val34Leu polymorphism in the A subunit of blood coagulation factor XIII (FXIII-A) is located in the activation peptide, just three amino acids upstream of the thrombin cleavage site. The $\mathrm{Val} \rightarrow$ Leu replacement accelerates the rate of the proteolytic activation of FXIII and it seems to provide protection against myocardial infarction. Methods available for the assessment of the FXIII-A Val34Leu polymorphism are rather time-consuming, laborious and not easily applicable for large-scale studies. In this study a new method based on real-time PCR with fluorescence resonance energy transfer (FRET) detection and melting curve analysis was developed. The rapid, simple method was adapted to the widely used real-time PCR instrument, LightCycler (Roche Diagnostics). The results showed $100 \%$ coincidence with those obtained by the traditional PCR-restriction fragment length polymorphism (RFLP) assay and fluorescent DNA sequencing. Using this method, an allele frequency of $24.2 \%$ was obtained $(n=113)$, which well agrees with the allele frequency obtained by PCR-RFLP on a different group of the same ethnic Hungarian population (25.9\%).
\end{abstract}

Keywords: factor XIII; fluorescence resonance energy transfer; gene polymorphism; real-time PCR.

Blood coagulation factor XIII (FXIII) is a zymogen of tetrameric structure $\left(A_{2} B_{2}\right)$; it consists of two potentially active $A$ subunits (FXIII-A) and two carrier/protective $B$ subunits (FXIII-B). FXIII is converted into an

\footnotetext{
*Corresponding author: Prof. László Muszbek, MD, PhD, Head, Clinical Research Center, Medical and Health Science Center, University of Debrecen, Thrombosis Research Group of the Hungarian Academy of Sciences, P. O. Box 40, 98 Nagyerdei krt. 4012 Debrecen, Hungary Phone: + 3652431956, Fax: +36-52-417631, E-mail: muszbek@jaguar.dote.hu
}

active transglutaminase (FXIIla) by the concerted action of thrombin and $\mathrm{Ca}^{2+}$. Thrombin cleaves off an activation peptide of 37 amino acid residues from the $\mathrm{N}$-terminus of FXIII-A, then in the presence of $\mathrm{Ca}^{2+}$ FXIII-B dissociates and FXIII-A assumes an enzymatically active configuration. FXIIla catalyzes the formation of glutaminyl-lysyl bonds between fibrin chains and covalently cross-links $\alpha_{2}$-plasmin inhibitor to fibrin. In this way FXIlla mechanically stabilizes the fibrin clot and increases its resistance to fibrinolysis [for reviews, see (1-3)]. FXIII-A is a rather polymorphic protein; five common polymorphisms resulting in amino acid replacement have been described (3). One of these polymorphisms, a $G \rightarrow T$ substitution in exon 2 resulting in $\mathrm{Val} \rightarrow$ Leu replacement at position 34 (4) (GenBank accession no. M21986), has attracted a lot of interest in the last couple of years. The frequency of the Leu34 allele among Caucasians is around $25 \%$, it is much lower in blacks and Asian Indians and extremely rare in the Japanese population. The site of the polymorphism is just three amino acids upstream of the thrombin cleavage site and it has been shown that the cleavage of the Leu34 variant, and consequently the activation of Leu34 FXIII, occurs significantly faster than that of the wild-type factor (5-7). In the first studies a protective effect of the Leu34 allele against myocardial infarction (8) and venous thrombosis (9) was reported. In follow-up studies both confirmatory and contradictory results were demonstrated [for a review, see (3)] and further large-scale studies seem to be required for clarifying the conditions under which the Leu34 allele exerts its protective effect.

In the epidemiological studies carried out so far, polymerase chain reaction (PCR) combined with single-stranded conformation polymorphism (SSCP) $(8,10)$ or restriction fragment length polymorphism (RFLP) $(5,11)$ detection, allele-specific PCR (12) or solid phase mini-sequencing (13) were used to distinguish among different Val34Leu FXIII-A genotypes. These methods are rather time-consuming, laborious and not easily applicable for large-scale studies. Here, we present an alternative approach based on realtime PCR with fluorescence resonance energy transfer (FRET) detection and melting curve analysis. This rapid, simple method was adapted to the widely used real-time PCR instrument, LightCycler (Roche Diagnostics, Mannheim, Germany).

DNA was isolated from citrated whole blood of 113 unrelated subjects [68 wild-type (V/V), 36 heterozy- 
gote (V/L), 9 homozygote (L/L)] using the MagNA Pure LC Instrument (Roche Diagnostics). Primers and probes were synthesized by TIB MOLBIOL (Berlin, Germany). The nucleotide compositions of primers and probes are shown in Table 1. The detection probe (sensor) labeled with fluorescein at the $3^{\prime}$ end covers the polymorphic site. A $\mathrm{C} \rightarrow \mathrm{A}$ mismatch was introduced in the sensor to decrease the melting temperature for both alleles. The adjacent anchor probe was $5^{\prime}$ labeled with LC Red640 dye and the $3^{\prime}$ end was phosphorylated to prevent probe elongation by Taq polymerase. The gap between the two probes is a single nucleotide. If the probes lie adjacent to each other on a DNA strand, fluorescence resonance energy transfer occurs and the fluorescence of LC Red640 is detected by the fluorimeter component of LightCycler.

$\mathrm{PCR}$ reactions were performed in the LightCycler glass capillaries in a final volume of $21 \mu$ l containing $150 \mathrm{ng}$ of genomic DNA, $0.19 \mu \mathrm{mol} / \mathrm{l}$ of each primer, $0.57 \mu \mathrm{mol} / \mathrm{l}$ of anchor probe, $0.38 \mu \mathrm{mol} / \mathrm{l}$ of sensor probe, $2 \cup$ Taq DNA polymerase (Roche), $2 \mu$ of $10 \times$ concentrated PCR reaction buffer (Roche), $42.9 \mathrm{ml} / \mathrm{l}$ dimethyl sulfoxide (Sigma; St. Louis, MO, USA), $0.48 \mathrm{mmol} / \mathrm{l}$ of each dNTP (Roche), plus an extra $2.86 \mathrm{mmol} / \mathrm{l}$ of $\mathrm{MgCl}_{2}$ (Roche). One sample without DNA, as a negative control, was included in all assay series. Cycling conditions were as follows: initial denaturation at $95^{\circ} \mathrm{C}$ for $30 \mathrm{~s}, 60$ cycles of denaturation at $94^{\circ} \mathrm{C}$ for $0 \mathrm{~s}$, annealing at $50^{\circ} \mathrm{C}$ for $5 \mathrm{~s}$ and extension at $72^{\circ} \mathrm{C}$ for $10 \mathrm{~s}$. Melting curve analysis consisted of one cycle at $94^{\circ} \mathrm{C}$ for $15 \mathrm{~s}$ and at $35^{\circ} \mathrm{C}$ for $15 \mathrm{~s}$, followed by increasing the temperature to $70^{\circ} \mathrm{C}$ at a $0.1^{\circ} \mathrm{C} / \mathrm{s}$ ramping rate. The fluorescent signal of $L C$ Red640 was monitored continuously during the temperature ramp and the results were transformed to derivative melting curves. Melting peak analysis easily discriminated the three different FXIII-A Val34Leu genotypes: melting temperature $\left(T_{m}\right)$ for the wild-type (Val/Val) was at $56.4^{\circ} \mathrm{C}$, while $\mathrm{T}_{\mathrm{m}}$ for the homozygote mutant (Leu/Leu) was at $47.5^{\circ} \mathrm{C}$; heterozygotes demonstrated both peaks (Figure 1).

One hundred and thirteen individual DNA preparations from a sample pool were tested by the method described above and by PCR-RFLP according to Balogh et al. (5). The results were in $100 \%$ concordance. The frequency of the Leu34 allele was $24.2 \%(95 \% \mathrm{Cl}$ : $16.3-32.1 \%)$, which agrees well with the allele frequency obtained by PCR-RFLP on a different group of the same ethnic Hungarian population $(25.9 \%$; $95 \% \mathrm{Cl}$ : 22.3-29.5\%) (5), and with the data reported for other Caucasian populations (14). Fifty randomly selected DNA samples (26 wild-type, 19 heterozygous and 5 homozygous for the FXIII-A Val34Leu polymorphism) were also evaluated by fluorescent DNA sequencing using the BigDye Terminator Reaction kit on an $\mathrm{ABI}$ 310 Genetic Analyzer (Applied Biosystems; Weiterstadt, Germany); again 100\% concordance was observed. To test the reproducibility of the assay, DNA samples of all three genotypes were retested on at least 20 different occasions. All results were consistent. Since the introduction of the assay, 500 patients' samples have been tested for the Val34Leu
Table 1 Primers and probes used for genotyping the FXIIIA Val34Leu polymorphism.

\begin{tabular}{ll}
\hline $\begin{array}{l}\text { Primers/ } \\
\text { probes }\end{array}$ & Sequence \\
\hline $\begin{array}{l}\text { Forward } \\
\text { primer }\end{array}$ & 5'-GAC CTT GTA AAG TCA AAA ATG TC-3' $^{\text {Reverse }}$ \\
primer & $5^{\prime}$-AA-GGG-GGG-TAT-GCT-CAT-3' \\
Sensor & $5^{\prime}$-G-CAC-A*AC-GCC-CTG-AAG-C-3'FL a,b \\
Anchor & $5^{\prime}$-LC Red640-C-CAC-TGT-GGG-CAG-GTC-ATC- \\
& TTC-C-3'-P \\
\hline
\end{tabular}

${ }^{\mathrm{a}} \mathrm{FL}$, fluorescein; $\mathrm{P}$, phosphorylated, ${ }^{\mathrm{b}}$ the site of the mutation is underlined; in the sensor a mismatch $(C \rightarrow A)$ was introduced at the position labeled with asterisk.

polymorphism in our laboratory, and in all cases a clear discrimination among the different FXIII-A Val34Leu genotypes has been observed.

Most recently, two real-time PCR methods, apyrasemediated allele-specific primer extension (15) and $5^{\prime}$ nuclease assay (16), were also adapted for genotyping the FXIII-A Val34Leu polymorphism. The results obtained by the assays were compared to those obtained by DNA sequencing on a relatively small number (17 and 20, respectively) of samples. Both methods seem to represent a promising alternative to earlier assays. However, as discrimination among different genotypes by these methods is based on quantitative measures, a comparison to reference methods on a larger number of samples is required to confirm their specificity. The real-time PCR method presented in this study uses FRET detection and differentiates among genotypes on the basis of a clear difference in the $T_{m}$ of wild-type and mutant allele. With LightCycler the amplification of the target DNA and determination of the genotype are performed in the same closed capillary, limiting the risk of error and contamination considerably. The LightCycler software provides a large amount of information from a single run. The assay is specific and reproducible, and the total analysis of 31 samples in the LightCycler takes less than $30 \mathrm{~min}$. Its specificity has been confirmed by comparison with the most frequently used PCR-RFLP

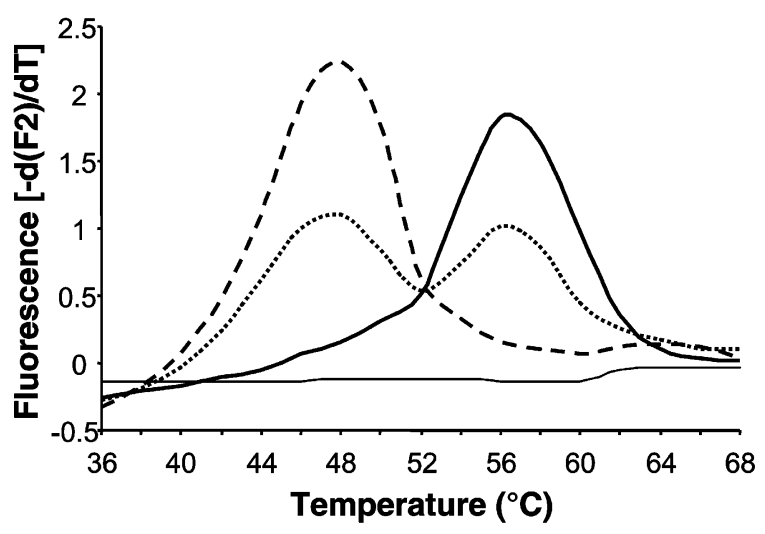

Figure 1 Representative derivative melting curves [ $-d(F 2) /$ dT vs. T] of the three FXIII-A Val34Leu genotypes. Thick solid line, V/V; dotted line, V/L; dashed line, L/L; thin solid line, no template control. 
method and with DNA sequencing on a large number of samples.

\section{Acknowledgements}

This work was supported by grants from the Hungarian National Research Fund (OTKA T043086, TS044796), from the Hungarian Academy of Sciences (MTA 11003) and from the Hungarian Ministry of Health and Social Affairs (ETT 355/ 2003).

\section{References}

1. Muszbek L, Ádány R, Mikkola H. Novel aspects of blood coagulation factor XIII. I. Structure, distribution, activation and function. Crit Rev Lab Sci 1996;33:357-421.

2. Muszbek L, Yee VC, Hevessy Z. Blood coagulation factor XIII: structure and function. Thromb Res 1999; 94:271-305.

3. Muszbek L, Bereczky Z, Katona É. Blood coagulation factor XIII: involvement in fibrinolysis and thrombosis. In: Arnout J, de Gaetano G, Hoylaerts N, Peerlinck K, Van Geet C, Verhaegghe R, editors. Thrombosis. Fundamental and clinical aspects. Leuven: Leuven University Press, 2003:197-224.

4. Mikkola H, Syrjälä M, Rasi V, Vahtera $E$, Hamalainen $E$, Peltonen L, Palotie A. Deficiency in the A-subunit of coagulation factor XIII: two novel point mutations demonstrate different effects on transcript levels. Blood 1994; 84:517-25.

5. Balogh I, Szöke G, Kárpáti L, Wartiovaara U, Katona É, Komáromi I, et al. Val34Leu polymorphism of plasma factor XIII: biochemistry and epidemiology in familial thrombophilia. Blood 2000;96:2479-86.

6. Ariens RA, Philippou H, Nagaswami C, Weisel JW, Lane DA, Grant PJ. The factor XIII V34L polymorphism accelerates thrombin activation of factor XIII and affects crosslinked fibrin structure. Blood 2000;96:988-95.
7. Wartiovaara U, Mikkola H, Szôke G, Haramura G, Kárpáti $L$, Balogh I, et al. Effect of Val34Leu polymorphism on the activation of the coagulation factor XIII-A. Thromb Haemost 2000;84:595-600.

8. Kohler HP, Stickland MH, Ossei-Gerning N, Carter A, Mikkola H, Grant P. Association of a common polymorphism in the factor XIII gene with myocardial infarction. Thromb Haemost 1998;79:8-13.

9. Catto AJ, Kohler HP, Coore J, Mansfield MW, Stickland $\mathrm{MH}$, Grant PJ. Association of a common polymorphism in the factor XIII gene with venous thrombosis. Blood 1999;93:906-8.

10. Anwar R, Gallivan L, Edmonds SD, Markham AS. Genotype/phenotype correlation for coagulation factor XIII: specific normal polymorphisms are associated with high or low factor XIII specific activity. Blood 1999; 93:897-905.

11. Kangsadalampai S, Board PG. The Val34Leu polymorphism in the A subunit of coagulation factor XIII contributes to the large normal range in activity and demonstrates that the activation peptide plays a role in catalytic activity. Blood 1998;92:2766-70.

12. Henry M, Morange PE, Canavy I, Alessi MC, Juhan-Vauge I. Rapid detection of factor XIII Val34Leu by allele specific PCR. Thromb Haemost 1999;81:463.

13. Wartiovaara U, Perola M, Mikkola H, Tötterma K, Savolainen $V$, Penttila $A$, et al. Association of factor XIII Val34Leu with decreased risk of myocardial infarction in Finnish males. Atherosclerosis 1999;142:295-300.

14. Muszbek L. Deficiency causing mutations and common polymorphisms in the factor XIII-A gene. Thromb Haemost 2000;84:524-7.

15. O'Meara D, Ahmadian A, Odeberg J, Lundeberg J. SNP typing by apyrase-mediated allele-specific primer extension on DNA microarrays. Nucleic Acids Res 2002;30:e75.

16. Tjarnlund A, Andersson M, Jood K, Ladenvall P, Jern C. Rapid genotyping of haemostatic gene polymorphisms using the $5^{\prime}$ nuclease assay. Thromb Haemost 2003;89:936-42.

Received January 19, 2004, accepted May 27, 2004 